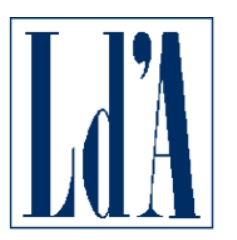

CENTRO STUDI LUCA D'AGLIANO

WWW.DAGLIANO.UNIMI.IT

\author{
CENTRO STUDI LUCA D'AGLIANO \\ DEVELOPMENT STUDIES WORKING PAPERS
}

N. 380

November 2014

Intellectual Property Rights and Diaspora Knowledge Networks

\author{
Alireza Naghavi* \\ Chiara Strozzi**
}

* University of Bologna and Centro Studi Luca d'Agliano

** University of Modena and Reggio Emilia and IZA 


\title{
Intellectual Property Rights and Diaspora Knowledge
}

\author{
Networks*
}

\author{
Alireza Naghavi ${ }^{\dagger} \quad$ Chiara Strozzi ${ }^{\ddagger}$
}

\begin{abstract}
This paper studies mechanism through which intellectual property rights (IPR) protection can influence the impact of skilled migration on innovation activities in developing countries. We argue that knowledge acquired by emigrants abroad can flow back to their country of origin through diaspora networks. IPR protection in the sending country magnifies this effect by increasing the size of the innovation sector, thereby allowing diaspora gains to fall on a larger range of workers. Strong IPR enforcement therefore makes it more likely for brain drain to be transformed into brain gain.
\end{abstract}

J.E.L. Classification: O30; F22; J24.

Keywords: Intellectual property rights; International migration; Innovation; Knowledge flows; Brain gain; Diaspora.

\footnotetext{
${ }^{*}$ We would like to thank Olena Ivus, Peter Kuhn, Elisabetta Lodigiani, Arsen Palestini, Hillel Rapoport, Gilles Saint-Paul, as well as the seminar participants at University of Lille 1, the University of Bologna, EEA 2011 Oslo, GLOBELICS 2010 Kuala Lumpur, GLOBELICS 2011 Buenos Aires, International Workshop on Economics of Global Interactions 2011 Bari, ITSG 2011 Milan, PRIN Workshop 2013 Bologna, RES 2012 Cambridge, and the WIPO Experts' Meeting on Intellectual Property, the International Mobility of Knowledge Workers and the Brain Drain 2013 Geneva for very helpful remarks. We gratefully acknowledge the European Commission for financial support through the 7th Framework Programme Project INGINEUS. Financial support from Fondazione Cassa Risparmio di Modena and from MIUR through the PRIN project "Institutions, Social Dynamics, and Economic Development" is also gratefully acknowledged.

${ }^{\dagger}$ Corresponding author: University of Bologna. Address: Department of Economics, University of Bologna, Piazza Scaravilli 2, 40126 Bologna, Italy. Phone: +39 051 2098873, Fax: +39 0512094080 , Email : alireza.naghavi@unibo.it.

${ }^{\ddagger}$ University of Modena and Reggio Emilia, IZA. Address: Department of Economics, University of Modena and Reggio Emilia, Viale Berengario 51, 41121 Modena, Italy. Phone: +39 059 2056850, Fax: 39059 2056947, Email: chiara.strozzi@unimore.it.
} 


\section{Introduction}

International trade and foreign direct investment (FDI) have often been identified as the main determinants of innovation and growth in developing countries (South) (Saggi, 2002; Keller, 2004). While the relevance of trade and FDI has been confirmed with a significant increase in their ratio to world output in the 1990's, high-skill migration from the South to OECD countries has also witnessed a remarkable growth in the same period (Docquier and Rapoport, 2012). The resulting surge in the outward transfer of the human capital in migrants has created controversial debates about the threats and opportunities that skilled emigration may pose to the South. On the one hand, the traditional literature on migration and brain drain presents mechanisms through which skilled emigration could be detrimental to growth. ${ }^{1}$ On the other hand, a growing branch of contributions argues that skilled emigration need not harm the South and may even increase the potential for development.

The so-called brain gain effect derives from an incentive channel that works through the increased expected returns to education brought about by migration prospects (Mountford, 1997; Stark et al. 2007; Beine et al., 2001, 2008). ${ }^{2}$ An additional channel is return migration, which can induce innovation through the knowledge possessed by migrants returning from more advanced economies (Domingues Dos Santos and Postel-Vinay, 2003; Mayr and Peri, 2009; Dustmann et al. 2011). Finally, cross-border diaspora networks among skilled emigrants and natives may also promote access to foreign-produced knowledge and foster innovation by encouraging trade, investments, and the recirculation of information back into the sending countries (Agrawal et al., 2011; Kerr, 2008). Sociological studies, such as Meyer (2001), suggest that such informal networks are crucial in turning brain drain into a net brain gain. Student/scholarly networks, local associations of skilled expatriates, short-term consultancies by high-skilled expatriates in their country of origins, and other unestablished intellectual/scientific diaspora networks are a few examples of such networks (Meyer and Brown, 1999). ${ }^{3}$

This research contributes to the literature by exploring the channel through which the knowledge learned by emigrants after interacting with higher skills in developed countries (North) can flow back to the South. We refer to this channel as an "intellectual diaspora", that is, the remote mobilization of intellectuals and professionals abroad and their connection to scientific, technological and cultural programs at home. ${ }^{4}$ This can be thought of as a scientist from the South being more productive in

\footnotetext{
${ }^{1}$ Seminal works include those of Berry and Soligo (1969), Bhagwati and Hamada (1974) and Miyagiwa (1991). For a recent complete survey of the literature on brain drain and development, see Docquier and Rapoport (2011).

${ }^{2}$ The possibilities of such gains from emigration were first referred to by Bhagwati and Rodrigues (1975).

${ }^{3}$ Williams (2007) and Oettl and Agrawal (2008) focus on the externalities of international migration to emphasize their role in knowledge and technology transfer. More recently, Beine et al. (2011) show the influence of diasporas on the evolution of migration flows and their composition in terms of skills.

${ }^{4}$ In this framework, the capacity of innovation of Southern innovators, who remain in their origin countries, is related to their access to valuable technological knowledge that is partially accumulated abroad (i.e., brain banks). For more on this issue, see Agrawal et al. (2011).
} 
the North due to better facilities and more resources, with some of the benefits of his innovation flowing back to his home country. Diaspora networks make this possible through the cross-border sharing of ideas, for example between Indian computer scientists in Bangalore and their counterparts in Silicon Valley (The Economist, 2009, 2011).

In such a framework, the goal of this paper is to assess the role of intellectual property rights (IPR) protection in the South in determining the impact of emigration on innovation activities in the home (sending) country. Motivated by the empirical findings in our companion study, Naghavi and Strozzi (2014), we aim to find a mechanism through which an appropriate level of IPR protection could help transform the brain drain caused by skilled emigration into a brain gain. In sum, we argue that although emigration may directly result in a brain drain, it also generates a flow of ideas and inventions back to the sending country, the extent of which depends on the strength of IPR protection.

The role of IPR protection in any study that involves innovation and the developing world is crucial. However, while the trade-offs faced by an emerging economy between imitation and the provision of incentives for domestic innovation through IPRs are clear (Maskus, 2000), the interrelationships between skilled migration and IPR policy in determining innovation remain to be explored. Our work fills this gap and contributes to the above-mentioned strand of research by capturing the diaspora dimension of migration and revealing how IPR protection in the sending country may influence the effect of skilled migration on innovation there. ${ }^{5}$ On this basis, we shed light on the net impact of emigration on innovation and determine whether a strong IPR regime at home can eventually turn the initial brain drain into a brain gain.

Our theoretical framework is a variant of the Yeaple (2005) and Ohnsorge and Trefler (2007) models of heterogeneous workers, where we introduce an innovation sector, migration, and IPR protection. Emigration reduces effective innovation activities due to the loss of the most skilled (the extensive margin). Migration, however, also opens a diaspora channel through which the knowledge acquired abroad can flow back into the innovation sector in the home economy and enhance the skills of the remaining workers (the intensive margin). To investigate whether the beneficial effect of diasporas could outweigh the direct negative effect of the outflow of skilled workers, we look at the size of the innovation sector. While a strong level of IPR protection directly reduces effective innovation activities by raising returns to skills and hence engaging also the less skilled mass of workers in the innovation sector, the enlarged sector allows diaspora gains to fall on a larger range of workers actively using their skills in the economy. As a consequence, a strong level of IPR protection in the sending country increases the magnitude of potential benefits from diaspora, making it more likely for the gains to outweigh the negative effects of brain drain on innovation, and thus facilitating

\footnotetext{
${ }^{5}$ Among the vast literature on intellectual property rights, Chen and Puttinan (2005) and Parello (2008) are perhaps most closely related to our work, as they specifically focus on domestic skill accumulation and innovation. While the former positively relates IPR protection to innovation, the latter deems it to be ineffective for innovation in less-developed countries.
} 
a potential net brain gain. ${ }^{6}$

In the remainder of the paper, we start by presenting some motivating evidence for our analysis in Section 2, present the theory in Sections 3 and 4, and conclude in Section 5.

\section{Some Motivating Evidence}

To motivate our theoretical analysis, we here present some evidence about the impact of diaspora knowledge networks on international scientific collaborations. The aim is to show whether migration to countries superior in terms of skills results in scientific collaboration between innovators in the countries involved and how this so-called international knowledge spillover is affected by home country IPR institutions. To do this, we apply a variant of the strategy proposed by Spilimbergo (2009) to investigate the transfer of norms across countries. On the basis of that intuition, the focus here is to construct a measure of emigration that includes information about "where" the emigrants go. Heterogeneity of the host countries is indeed important as the intensity of knowledge transferred back to the countries of origin could depend on how technologically advanced is the destination country. The underlying assumption is that emigrants may better promote innovation in their home countries if their host countries have a higher potential for innovation. This approach allows us to confirm that it is the skills learned from abroad by emigrants and transferred back to their home country that increase international scientific collaboration, provided that IPR institutions are strong in the country of origin.

While Spilimbergo (2009) argues that foreign-trained individuals promote democracy in their home countries if they study in democratic countries, we here argue that in the presence of strong home country IPRs, emigrants promote innovation in their home countries if their host countries have a high potential for innovation. To capture heterogeneity among destination countries, for each country of origin we construct an emigration measure based on bilateral emigration stocks between that country and its destination countries and a measure of the potential for innovation in each host country. The emigration measure of origin country $i$ is defined as

$$
\text { emig }_{i t}=\sum_{j} \frac{m_{i j t}}{M_{i t}} I_{j t}
$$

where $i$ is the origin country, $j$ is destination country and $t$ denotes time. $m_{i j}$ is the bilateral emigration stock from country $i$ to country $j, M_{i}$ is total emigration stock from country $i$, and $I_{j}$ is a measure of innovation in country $j$. This emigration measure is by construction an index

\footnotetext{
${ }^{6}$ These results are in contrast to the theoretical conclusion obtained by McAusland and Kuhn (2011), who claim IPRs to be an obstacle to the international flow of brains. In short, they argue that if brains are emigrating, a country may as well lower its IPRs to free-ride on brains that have moved elsewhere. While their study is to our knowledge the first contribution that explicitly investigates the link between IPRs and brain circulation, it does not take into account any channels through which the skills acquired abroad can be transferred back into the country of origin.
} 
which lies between 0 and 1 ; the index is 1 if all emigrants go to the countries with very high innovation potential and 0 if all emigrants are in countries with very low potential for innovation. The innovation indicators we consider are the total number of worldwide patents granted to the residents of each destination country per thousand of population and the $R \& D$ expenditure in the destination country. ${ }^{7}$

To get an appropriate measure of the globalized nature of knowledge and its worldwide circulation, as proxy of international scientific collaboration (i.e. the dependent variable of our empirical exercise) we use the number of inventors from around the world which reside in a country different from that of the PCT applicant. The measure is taken from Section A.6.2 of World Intellectual Property Indicators (WIPO, 2012) and expresses the number of PCT applications having at least one foreign inventor, broken down by inventor's (not applicant's) origin. For example, around twothirds of Indian inventors named in PCT applications were associated with foreign PCT applications in India. This is also an indication of how many foreign firms apply for patents in India using as inventors at least one resident of India. This measure is available annually since 2000.

Finally, our measure of IPR protection is taken from Park (2008) and represents an index of the strength of patent protection for each country as an unweighted sum of five separate scores for the following: coverage, membership in international treaties, duration of protection, enforcement mechanisms, and restrictions. The Park data on IPR protection are available from 1960 to 2005 in five-year intervals.

To investigate whether emigration is more likely to result in brain gains under stronger IPR regimes, we explicitly focus on the interrelationships between IPR protection and emigration into countries with superior skills. To this end, we study the determinants of innovation with the help of an empirical specification that introduces the following key variables: the emigration index, the index of IPR protection and the interaction between the two. The sample we use is composed of 35 emerging and developing countries (chosen on the basis of data availability) and the time interval for the dependent variable ranges from 2000 till 2010. As the data on IPRs are only available every five years, our estimations are based on five-years intervals: in this way, we are left with three observations for each country throughout the sample period. In our quinquennial sample all independent variables are lagged one period (i.e. five years). Lagging the emigration index and IPR protection allows for the time needed for emigrants to acquire skills and interact to transfer knowledge to their home countries and for patents to be granted. This makes years 2000-2010 the relevant period to observe international scientific collaboration, and 1995 - 2005 the lagged period of observation for the independent variables. All estimations are performed using panel fixed effects regression methods and include period dummies.

\footnotetext{
${ }^{7}$ Bilateral annual migration data have been kindly provided by Mariola Pytlikova and collect information from different statistical offices of the world, supplemented by OECD statistics. For details on earlier versions dataset, see Pedersen et al. (2008). Innovation measures are taken from WIPO and the World Bank.
} 
The baseline specification we adopt is the following:

$$
\begin{aligned}
\text { inv }_{i t}= & \beta_{0}+\beta_{1} \text { emigr }_{i t-1}+\beta_{2} I P R_{i t-1}+\beta_{3} \text { emigr }_{i t-1} I P R_{t-1}+ \\
& +\gamma p o p_{i t-1}+\delta g d p p c_{i t-1}+\alpha_{i}+\eta_{t}+\varepsilon_{i t}
\end{aligned}
$$

where $i$ denotes the country and $t$ the year. The dependent variable $i n v_{t}$ is our measure of international scientific collaboration. The variable emigr $_{t-1}$ represents the lagged emigration index, $I P R_{t-1}$ is the lagged measure of IPR protection, and emigr $r_{t-1} I P R_{t-1}$ is the lagged interaction term between the emigration index and IPR protection. The cumulative effect of emigration to more scientifically advanced destinations on innovation is then captured by $\beta_{1}$ and $\beta_{3} I P R_{t-1}$ and varies with the level of IPR protection. $p o p_{t-1}$ and $g d p p c_{t-1}$ are population and GDP per capita, which are included to account for size effects. Finally, the $\alpha_{i}$ 's are time-invariant country-specific effects, the $\eta_{t}$ 's are period dummies, and $\varepsilon_{i t}$ is the error term. The results of our empirical exercise are shown in Table 1 below.

\section{[TABLE 1 ABOUT HERE]}

Column 1 of the table shows the emigration measure based on total patents in the world owned by residents of the destination country, whereas column 2 uses R\&D expenditure in destination to build the same measure. As we can see from the coefficients of the interaction in both cases, the impact of emigration on innovation is positive and highly significant in the presence of strong IPR protection. Hence, IPRs have a role in promoting the beneficial effects of the diaspora channel of knowledge. ${ }^{8}$ Interestingly, South-North emigration without stringent enforcement of IPRs in the home country instead leads a brain drain. These results suggest that diasporas in innovative destinations play an important role in the transfer of skills and brain gain. More central to our analysis, IPR protection can reduce brain drain and even increase the brain gain impact of emigration in terms of international innovation collaboration in less-developed countries.

\section{The Model}

\subsection{The Basic Framework}

Suppose there are two regions: a developing economy referred to as the South and an alternative North with better economic opportunities and employment possibilities, where skills and wages are assumed to be higher. Because the focus of our study is the southern market, we concentrate our

\footnotetext{
${ }^{8}$ We have added several other (origin) country-specific control variables on top of the country fixed effects, such as patent stock, tertiary education, resident patents, non-resident patents, R\&D expenditure and total agriculture share. Most of the chosen variables result not significant or barely significant while the predictions on our main variables of interest remain unchanged.
} 
analysis on goods invented, produced and consumed locally in the South. ${ }^{9}$ Consumers have the following utility function:

$$
U_{i}=C_{i}=\left[\int_{0}^{N} c_{j}^{\alpha} d i\right]^{\frac{1}{\alpha}},
$$

where individual consumption $C_{i}$ is divided between a continuum of $N$ invented goods subscripted by $j \in(0, N)$, and $\alpha \in(0,1)$ represents the inverse measure of product differentiation.

There are two sectors in the economy: a production and an innovation sector. Labor is the only factor of production and innovation and is mobile between sectors. Workers are spread over a continuum of skills $z \in[0, \infty)$, distributed with density $g(z)$ and cumulative distribution $G(z)$. We normalize the mass of workers to one. Define $z_{1}$ the skills of a threshold worker indifferent between working in the production or the innovation sector and $z_{2}$ the threshold above which workers choose to migrate. Throughout the rest of the model, we make the assumption that $z_{1}<z_{2}<\infty$, in order to allow a positive and finite level of migration. ${ }^{10}$

While production does not require skills, a worker $i$ with skills $z_{i}$ in the innovation sector has productivity $h_{i}$ such that

$$
h_{i}(z)=z_{i}+Z
$$

where $z_{i}$ represents own skill endowment and $Z$ (defined below) is the international spillover of knowledge learned by emigrants abroad through what we call the "diaspora" channel. We are interested in observing the initial skill endowment of each individual (their innate ability) used in the innovation sector and how the assumed superior knowledge from the North can flow back to upgrade workers' productivity.

The timing of the model is as follows. Nature reveals the IPR regime, which is assumed to be exogenous to our model. Emigration takes place in period 0, activating the diaspora channel. Innovation is then carried out in the first period, and production occurs in the second.

Emigration in period 0 is modeled as a movement of labor from the South to the North at a $\operatorname{cost} F$, which allows only the highest skilled to move. Potential diaspora is then realized by means of skilled emigrants transferring their newly acquired knowledge back to the South. We define the positive externalities from diaspora networks as

$$
Z=b \zeta(z)
$$

\footnotetext{
${ }^{9}$ Using a reduced form model that abstracts from trade and FDI related issues allows us to single out the impact of South-North migration, but clearly does not provide definitive answers to how IPRs and diasporas interact. See Iranzo and Peri (2009) for a study of trade and migration and Davis and Naghavi (2011) for the effects of trade and offshoring on innovation within the same occupational choice setting. These papers however do not deal with the issue of IPRs.

${ }^{10}$ See the Appendix for the feasibility of the assumption.
} 
where the skills endowment of those who migrate to the North is

$$
\zeta(z)=\int_{z_{2}}^{\infty} z g(z) d z
$$

Parameter $b \geq 0$ measures the intensity of diaspora gains, which is influenced by factors such as the level of academic and professional interactions and the amount of skills learned in the North, or the successful transmission of knowledge to and the absorptive capacity of the South. This measure can also be thought of as to how much innovations undertaken by emigrants abroad are still suitable to serve the southern economy, a concept referred to as a negative "expatriate brains" effect in McAusland and Kuhn (2011). Note that $b=0$ implies no international knowledge transfer, $b=1$ the return of only original (pre-migration) skills of emigrants, and $b>1$ the diffusion of their improved skills to the South.

In period 1, $N$ goods are invented. Each good needs $\rho$ units of skills. The total amount of human capital in the economy can be written as

$$
H(z)=\int_{z_{1}}^{z_{2}} h_{i} g(z) d z
$$

The total number of inventions available for consumption are in turn

$$
N=N(z)=H(z) / \rho
$$

To work in the innovation sector, each worker must go through training at a cost $e$, which is paid in the second period. The wage per unit of skill for the high-skilled in the innovation sector is $\omega_{H}$ and is paid in period 2, giving each individual with skills $z_{i}$ a wage equivalent to $h_{i} \omega_{H}$.

In period 2, the production sector absorbs all workers who have not worked in the innovation sector in the first period. The production function is CRS in labor and has a productivity equal to one such that there is a one-to-one relationship between output and labor, $n_{j}=l_{j}$. Individual wage is identical for all workers in this sector and equals $\omega_{L}$.

\subsection{Patents and Consumption}

We use the basic framework presented in Saint-Paul $(2003,2004)$ as our benchmark, modeling IPR protection as the probability that an innovator can obtain monopoly power over his invention. ${ }^{11}$ The probability of being granted a patent is $q$, which captures the degree of IPR protection. ${ }^{12} \mathrm{~A}$ nonpatented good can be imitated driving its price down to the marginal cost of production normalized

\footnotetext{
${ }^{11}$ Saint Paul (2004) uses this setting to explore the implications of IPRs and redistribution on occupational choice and welfare.

${ }^{12}$ Grossman and Lai (2004) also model patent protection in a similar manner.
} 
to one. This also determines wages in the production sector, $p_{L}=\omega_{L}=1$. Otherwise, if a patent is granted, a firm charges monopoly price $p_{M}=\mu$, which includes a mark-up over marginal cost:

$$
\mu=1 / \alpha
$$

Next, consumption is divided between patented and non-patented goods, $c_{P}$ and $c_{N}$, respectively. Consumers allocate their income $y$ (net of training costs) between the two types of goods by maximizing (1) or equivalently

$$
\underset{c_{N}, c_{P}}{\operatorname{Max}} N q c_{P}^{\alpha}+N(1-q) c_{N}^{\alpha}
$$

under the budget constraint

$$
y=N q \mu c_{P}+N(1-q) c_{N}
$$

The solution to the above maximization problem is:

$$
c_{N}=\frac{y}{\psi}, c_{P}=\frac{y}{\psi} \mu^{\frac{1}{(\alpha-1)}}
$$

where

$$
\psi=N(1-q)+N q \mu^{\frac{\alpha}{(\alpha-1)}}
$$

captures the love of variety effect as $\partial \psi / \partial N>0$ and the disutility caused by monopoly pricing as $\partial \psi / \partial q<0$.

Using (1), (8), (10) and (11), aggregate consumption index is therefore

$$
C=\frac{y}{\psi^{\frac{(\alpha-1)}{\alpha}}}=\frac{y}{P},
$$

where $P=\psi^{\frac{(\alpha-1)}{\alpha}}$ is the aggregate price index.

The value of a patent, which is equal to monopoly profits, is equal to

$$
\pi=(\mu-1) \frac{Y \mu^{\frac{1}{(\alpha-1)}}}{\psi}
$$

where $Y$ is aggregate income (net of training cost). In the above expression, the first term on the right-hand side (RHS) is the mark-up, whereas the second is total demand for the patented good.

Under a competitive labor market, expected profit from inventing a new good must equal to its cost in terms of skills such that

$$
q \pi=\rho \omega_{H}
$$

Using (12), this gives

$$
\omega_{H}=q(\mu-1) Y \mu^{\frac{1}{(\alpha-1)}} / \psi \rho .
$$


Replacing for $\psi$ from (11) and recalling that $\mu>1$, stronger patent protection (higher $q$ ) increases wages in the innovation sector $\omega_{H}$ as

$$
\frac{\partial \omega_{H}}{\partial q}=\frac{(\mu-1) Y \mu^{\frac{1}{(\alpha-1)}} \rho N}{\psi^{2} \rho^{2}}>0
$$

for a given level of aggregate income. More stringent IPR enforcement protects inventors against imitation making it more attractive to work in the innovation sector.

\subsection{Migration}

To determine the migration threshold skill level $z_{2}$, suppose a worker migrates to the North if his gains from doing so, net of migration costs, exceed what he would earn in the innovation sector at home:

$$
\omega_{M} z_{i}-e-F>\omega_{H} h_{i}-e \Rightarrow \omega_{M} z_{2}-F=\omega_{H} z_{2}+\omega_{H} Z \Rightarrow z_{2}=\frac{F+\omega_{H} Z}{\omega_{M}-\omega_{H}},
$$

where we assume an exogenous wage in the innovation sector of the North higher than that in the South: $\omega_{M}>\omega_{H} \cdot{ }^{13}$ Suppose a positive level of migration is triggered by a reduction in $F$. We can state

Lemma 1 A reduction in the fixed cost of migration encourages emigration of skills to the North $\left(\frac{\partial z_{2}}{\partial F}>0\right)$, but opens a channel for potential diaspora gains $\left(\frac{\partial \zeta(z)}{\partial z_{2}}<0\right)$.

Proof. Follows directly from (4) and (15).

It follows from Lemmas 1 that a reduction in migration costs $F$ spurs the brain drain syndrome, decreasing the size of the innovation sector by a movement of workers from the upper tail of the distribution of skills out of the country. At the same time migration creates an opportunity for new knowledge to flow into the country through an increased number of skilled migrants abroad $\zeta(z) .{ }^{14}$

\subsection{Intellectual Property Rights Protection}

To pin down the threshold skill level $z_{1}$ above which individuals choose to train and work in the innovation sector, consider a worker with productivity $h_{i}$, who can either work in the innovation sector and earn $\omega_{H} h_{i}-e$, where $\omega_{H}>1$, or become a production worker with wage $\omega_{L}=1$. Choosing the option that generates a higher income, a worker self-selects to work in the innovation

\footnotetext{
${ }^{13}$ Note that although workers take into account the potential benefits from international spillovers made possible through migration by others, in a perfectly competitive labor market they take wages as given and do not consider the effect of their own move on $Z$.

${ }^{14}$ In addition, higher prospective wages abroad $\omega_{M}$ encourage the flow of skills away from the country, whereas higher wages in the innovation sector at home $\omega_{H}$ reduce skilled emigration. Higher potential gains from diaspora $Z$ similarly discourage migration as individuals are aware that they can partially enjoy the knowledge acquired by others who emigrate without bearing the costs of migration themselves.
} 
sector if

$$
\omega_{H} h_{i}-e>1 \Rightarrow \omega_{H} z_{i}+\omega_{H} Z-e>1 \Rightarrow z_{1}=\frac{1+e-\omega_{H} Z}{\omega_{H}} .
$$

Lemma 2 IPR protection increases returns to skills in the South $\left(\frac{\partial \omega_{H}}{\partial q}>0\right)$ by blocking imitation, shifting workers from the production to the innovation sector $\left(\frac{\partial z_{1}}{\partial \omega_{H}}<0\right)$.

Proof. Follows directly from (14) and (16).

It follows from Lemmas 2 that better IPR enforcement $q$ attracts production workers to the innovation sector by reducing imitation, thereby increasing the returns to working in that sector $\left(\omega_{H}\right) \cdot{ }^{15}$ The impact of IPR enforcement on the southern labor market in the absence of migration is illustrated in Figure 1.

\section{[FIGURE 1 ABOUT HERE]}

Next we look at the effect of IPR protection on the migration decision of innovation workers. A look back at (15) shows that the threshold skill level $z_{2}$ increases in wages $\omega_{H}$ as $\frac{\partial z_{2}}{\partial \omega_{H}}>0$, that is, higher skilled wages in the South discourage emigration to the North. It follows:

Lemma 3 Higher returns to skills obtained through IPR protection retain skilled workers in the home innovation sector $\left(\frac{\partial z_{2}}{\partial \omega_{H}}>0\right)$ and reduce the size of diasporas $\left(\frac{\partial \zeta(z)}{\partial z_{2}}<0\right)$.

Proof. Follows directly from (4), (14) and (15).

Lemma 3 suggests that IPR protection works as a force against brain drain by preserving skills in the South. An improvement in the IPR protection level $q$ partially prevents migration by recognizing the rights of inventors and discouraging imitation. A change in $z_{2}$ also changes the composition of international spillovers that effect workers' productivity. Namely, reduced migration induced by IPRs limits potential gains from diaspora by encouraging more skilled workers to remain in the home economy.

\subsection{General Equilibrium}

The economy is in equilibrium when the allocation of workers across sectors is compatible with the labor and product market clearing conditions. The total number of workers in the production sector in terms of the threshold skill level $z_{1}$ is

$$
L=L\left(z_{1}\right)=\int_{0}^{z_{1}} g(z) d z=G\left(z_{1}\right)
$$

\footnotetext{
${ }^{15}$ In addition, higher training costs $e$ prevent entry by the low-skilled, whereas higher wages in the innovation sector at home $\omega_{H}$ and higher potential diaspora gains $Z$ increase returns to working in the innovation sector, thereby shifting workers there.
} 
and total skills in the innovation sector in terms of $z_{1}$ and $z_{2}$ is expressed by

$$
H(z)=H\left(z_{1}, z_{2}\right)=\int_{z_{1}}^{z_{2}} h_{i} g(z) d z
$$

Market clearing implies that the total output net training cost $Y$ is equal to the total factor income: ${ }^{16}$

$$
Y=\omega_{H} H\left(z_{1}, z_{2}\right)+L\left(z_{1}\right)
$$

This equilibrium condition can equivalently be written through the labor market clearing condition

$$
L\left(z_{1}\right)=[N(1-q)] \frac{Y}{\psi}+N q \frac{Y \mu^{\frac{1}{(\alpha-1)}}}{\psi},
$$

where the first and the second term on the RHS derive from the total consumer demand for the non-patented and patented goods, respectively.

We can close the model by using equations (6), (11), (13), and (19) to solve for the equilibrium wage in terms of $z_{1}$ and $z_{2}$ :

$$
\omega_{H}=\omega_{H}\left(z_{1}, z_{2}\right)=\frac{q(\mu-1) \mu^{\frac{1}{(\alpha-1)}} L\left(z_{1}\right)}{H\left(z_{1}, z_{2}\right)\left[1-q\left(1-\mu^{\frac{1}{(\alpha-1)}}\right)\right]} .
$$

An increase in $q$ on the RHS of $(21)$ is always compensated by a fall in $z_{1}$ (as $\partial L\left(z_{1}\right) / \partial z_{1}>$ 0 in the numerator and $\partial H\left(z_{1}, z_{2}\right) / \partial z_{1}<0$ in the denominator) and an upward shift in $z_{2}$ (as $\left.\partial H\left(z_{1}, z_{2}\right) / \partial z_{2}>0\right)$ to maintain equilibrium. Using (21) together with (16), (15), we obtain the following two-equation system:

$$
\begin{aligned}
\omega_{H}\left(z_{1}, z_{2}\right)\left(z_{1}+Z\right) & =1+e \\
\omega_{H}\left(z_{1}, z_{2}\right)\left(z_{2}+Z\right) & =\omega_{M} z_{2}-F .
\end{aligned}
$$

Using (21) to rewrite the equilibrium condition (22) and dividing each side of the two equations, it is easy to see that thresholds $z_{1}$ and $z_{2}$ must move in opposite directions:

$$
\frac{\omega_{M} z_{2}-F}{z_{2}+Z}=\frac{1+e}{z_{1}+Z}
$$

The RHS of (23) is clearly decreasing in $z_{1}$ and increasing in $z_{2}$ as $\partial Z / \partial z_{2}<0$. The LHS is also strictly increasing in $z_{2}$ as

$$
\frac{\partial L H S}{\partial z_{2}}=\frac{\omega_{M} Z+F+\frac{\partial Z}{\partial z_{2}}\left(F-\omega_{M} z_{2}\right)}{\left(z_{2}+Z\right)^{2}}>0,
$$

\footnotetext{
${ }^{16}$ In the following, we assume training costs $e$ to be embedded in $Y$, which simplifies the notation but does not influence the results.
} 
where $\frac{\partial Z}{\partial z_{2}}<0$ and $F-\omega_{M} z_{2}<0$ from (15). Thresholds $z_{1}$ and $z_{2}$ must therefore move in opposite directions, i.e., $\partial z_{2} / \partial z_{1}<0$, to maintain equilibrium. We can state

Lemma 4 An exogenous shock to the economy always causes the innovation sector to either expand or contract from both ends $\left(\frac{\partial z_{2}}{\partial z_{1}}<0\right)$.

Proof. Derives from (21) and derivations in (22)-(24).

Lemma 4 states that in general equilibrium, the reallocation of workers in the economy caused by migration or IPR protection either reduces or increases the size of the innovation sector from both sides of the distribution. It will be seen below how this general equilibrium effect reinforces our key results. We can now calculate the dynamics of $z_{1}$ and $z_{2}$ with respect to changes in the IPR regime, $q$, and subsequently analyze how skilled emigration could promote innovation in the South. We then explore the conditions under which the beneficial effects of cross-border diaspora are likely to outweigh the negative brain drain effect of emigration and transform it into brain gain.

\section{Diasporas and Innovation}

This section studies the combined effect of IPRs and migration on innovation in the sending country through the diaspora channel, i.e. the spillover of superior knowledge learned by migrants back to their original country. Such potential gains from skilled migration are denoted by $Z$ in equation (3) and illustrated in Figure 2. The aim is to show that although a reduction in migration costs $F$ hurts South's innovations via brain drain by inducing the marginal emigrant to leave (Lemma 1), it also helps the southern inframarginal innovators via diaspora feedbacks. The extent to which such feedbacks create gains for the sending country depends on the size of the innovation sector, itself determined by the level if IPR enforcement.

\section{[FIGURE 2 ABOUT HERE]}

To start, observing Lemmas 2-4 reveals that IPR protection increases the size of the innovation sector from both spectrums:

Proposition 1 IPRs fosters potential gains from diaspora by expanding the size of the innovation sector from both sides of the spectrum $\left(\frac{d z_{1}}{d q}<0, \frac{d z_{2}}{d q}>0, \frac{d z_{2}}{d z_{1}}<0\right)$ by attracting less skilled workers into the innovation sector and discouraging skilled workers from migration.

Proof. Follows directly from Lemmas 2-4 with the formal proof in the Appendix.

Proposition 1 states that for any given $F$ that yields a positive level of migration, more stringent IPR protection allows potential gains from diaspora, $Z$, to fall on a larger range of workers active in the innovation sector. It will be seen below that this effect of IPRs can create net gains from diasporas 
despite of reducing the number of migrants, as long as the intensity of international knowledge flows is sufficiently high (large $b$ ). The change in the magnitude of the diaspora mechanism cause by stronger IPRs is depicted in Figure 3.

\section{[FIGURE 3 ABOUT HERE]}

We can also directly derive the consequences of strengthening IPR enforcement on innovation in the South by calculating the effect of a change in the IPR regime on the number of inventions, $N(z)$.

Corollary 1 The IPR protection increases the number of innovations by driving more workers into the home innovation sector, but also decreases it by limiting migration and hence reducing the amount of diaspora knowledge spillovers. The total effect is therefore ambiguous $\left(\frac{d N\left(z_{1}, z_{2}, q\right)}{d q} \lessgtr 0\right)$.

\section{Proof. See Appendix A.1.}

It is worth mentioning that the size of innovation sector here is proportional to the number of inventions, $N(z)$, which is itself directly determined by the amount of human capital in the innovation sector, $H(z)$. In an alternative framework, average skills in the innovation sector can also play a role in the productivity of innovation workers, $h(z)$. This concept is for example used in the production function of Helpman, Itskhoki and Redding $(2009,2010,2011)$ to show how the productivity of a worker may depend on the average productivity of his team or how managerial time can be a constraint when a given amount of attention needs to be allocated among workers. Introducing this feature creates a secondary (direct) negative effect of IPR enforcement on innovation because average skills and hence research productivity is reduced as less talented workers become researchers. Although this effect reinforces the empirical findings of Naghavi and Strozzi (2011), we abstract from it in the model for the sake of exposition as it is unnecessary to obtain our results. It will be seen below that IPRs regardless create the conditions for new knowledge from diasporas, $Z$, to benefit a larger number of innovation workers in the intensive margin, both the less and the more skilled.

We are now in the position to make some conclusions about how IPR protection influences the effect of migration on innovation activities in the sending country. Recall from (6) that the number of innovations in the South is proportional to $H(z)$, which according to Equations (2) and (5) depends both on the size of the innovation sector and the potential gains from diaspora. To measure the net effect of migration on innovation in the South, we must weigh the magnitude of the negative brain drain effect against gains brought about by the diaspora channel. To make the point, let's first consider a shift from a no-migration scenario to one with a positive level of migration. Brain drain can be summarized as the direct loss of skills embedded in workers who migrate abroad, i.e., the extensive margin. This is, in other words, the amount of skills initially available prior to migration 
minus the base skills of the remaining workers post-migration:

$$
B D=\int_{z_{1}}^{\infty} z g(z) d z-\int_{z_{1}}^{z_{2}} z g(z) d z=\int_{z_{2}}^{\infty} z g(z) d z
$$

Next, we rewrite the aggregate supply of skills as

$$
H\left(z_{1}, z_{2}\right)=\int_{z_{1}}^{z_{2}}(z+Z) g(z) d z=\int_{z_{1}}^{z_{2}} z g(z) d z+b \zeta(z) \int_{z_{1}}^{z_{2}} g(z) d z
$$

The first term on the RHS represents the amount of skills workers in the innovation sector are originally endowed with and the second term the aggregate diaspora effect on the same workers still residing in the South, i.e., the intensive margin. ${ }^{17}$ The second term on the RHS of (26) denotes the virtual return of upgraded skills through diasporas and can be rewritten to define brain gain as

$$
B G=b \zeta(z) \int_{z_{1}}^{z_{2}} g(z) d z=b\left[G\left(z_{2}\right)-G\left(z_{1}\right)\right] \int_{z_{2}}^{\infty} z g(z) d z
$$

where $\left[G\left(z_{2}\right)-G\left(z_{1}\right)\right]$ represents the size of the innovation sector, which is then multiplied by the diaspora term $b \zeta(z)$ to account for the total effect of the latter on innovation in the home economy. Recall that an improvement in the IPR regime increases returns to skills (working in the innovation sector) by increasing wages $\omega_{H}$. This results in an expansion of the innovation sector by reducing $z_{1}$ and increasing $z_{2}$. The RHS of Equation (27) reveals that protecting IPRs increases the number of workers in the innovation sector who can benefit from diaspora by enlarging $\left[G\left(z_{2}\right)-G\left(z_{1}\right)\right]$. However it also reduces the size of diasporas (number of migrants) and the amount of potential knowledge they can send back.

To determine whether the brain gain effects caused by a diaspora channel could dominate the flight of skills caused by brain drain, we must calculate the net effect of migration on total human capital in the sending country and test whether

$$
\begin{aligned}
B D-B G & \gtrless 0 \\
\int_{z_{2}}^{\infty} z g(z) d z-b\left[G\left(z_{2}\right)-G\left(z_{1}\right)\right] \int_{z_{2}}^{\infty} z g(z) d z & \gtrless 0 \\
b\left[G\left(z_{2}\right)-G\left(z_{1}\right)\right] & \equiv \Phi \gtrless 1 .
\end{aligned}
$$

As seen above, the term $\Phi \equiv b\left[G\left(z_{2}\right)-G\left(z_{1}\right)\right]$ can take a value greater or less than one. Brain gains through diaspora dominate when $\Phi>1$, which is more likely for high levels of IPR protection because $\frac{\partial z_{1}}{\partial q}<0 \Rightarrow G^{\prime}\left(z_{1}\right)>0 \Rightarrow \frac{\partial \Phi}{\partial z_{1}}<0$ and $\frac{\partial z_{2}}{\partial q}>0 \Rightarrow G^{\prime}\left(z_{2}\right)>0 \Rightarrow \frac{\partial \Phi}{\partial z_{2}}>0$. As a result, IPRs makes

\footnotetext{
${ }^{17}$ Note that emigrants are excluded when summing up local skills in the South.
} 
it more likely for skilled migration to generate brain gains by increasing the size of the innovation sector. Also the intensity of international spillovers $(b)$ must be large enough to compensate for the negative diaspora effect of IPRs through reduced stock of knowledge that can be sent back $(\zeta(z))$.

Proposition 2 Gains from diaspora could outweigh the direct loss of skills caused by migration if the IPR level in the South and intensity of knowledge spillovers are sufficiently high such that $b\left[G\left(z_{2}\right)-G\left(z_{1}\right)\right] \equiv \Phi>1$. IPRs furnish the conditions for knowledge from diasporas to reach out to a larger number of workers in the innovation sector $\left(\frac{d\left[G\left(z_{2}\right)-G\left(z_{1}\right)\right]}{d q}>0\right)$.

Proof. Derives from Lemma 1 and Proposition 1 together with (28).

Looking at the problem from a broader perspective, we can also calculate the effect of an exogenous reduction in migration costs $F$ on the number of innovations in the South and how the sign of the change depends on the IPR regime.

Corollary 2 Migration induced by a lower $F$ results in a drain of existing skills utilizable in the innovation sector, but increases the possibility for superior knowledge to be learned and sent back from diasporas. Stronger IPR protection in the South makes it more likely for the latter positive effect to dominate so that $\left(\frac{d N\left(z_{1}, z_{2}, q\right)}{d F}<0\right)$.

\section{Proof. See Appendix A.2.}

Interestingly, the results produced by the model are compatible with the alternative explanations provided in Beine et al., (2001) and Mayr and Peri (2009) on human capital development and return migration respectively. To compare, IPRs work as an intermediary channel to extract (brain) gains from skilled migration by encouraging education in the home country. Similarly, IPRs induce return migration of workers with enhanced skills back into the innovation workers. We can therefore conclude that when skilled migration generates positive knowledge flows, IPR protection creates the conditions for the southern innovation sector to absorb benefits from diasporas by stimulating human capital development, return migration, or intellectual diaspora networks.

\section{Conclusions}

In this paper, we have explored the link between cross-border diaspora networks and innovation capacity in migrants' countries of origin. The perspective we adopt is that of a developing country. We argue that although skilled emigration out of a developing country may directly result in the well-known concept of brain drain, it can also cause an indirect brain gain effect, the extent of which depends on the level of intellectual property rights protection in the country of origin. While the literature on brain gain and development highlights that the brain gain channel is realized through an increase in the incentives for human capital formation in the sending countries, in our framework 
the brain gain channel is realized through an increase in the size of the innovation sector. Both interpretations, however, lead to the same conclusion: under certain conditions, skilled emigration could be beneficial for growth in the sending countries.

We investigate under what circumstances skilled emigration may be beneficial for development. We show that this occurs in the presence of a strong IPR regime, which may turn a brain drain into a brain gain. IPR protection influences a country's potential for innovation by changing the size of the innovation sector. This could increase the absorptive capacity of the emigrants' country of origin, thus leading to more beneficial effects from cross-border diaspora networks.

The mechanism at work is as follows. Emigration has two effects. On the one hand, it decreases the amount of skills in the innovation sector by losing the most skilled through a lower $z_{2}$ (the extensive margin). On the other hand, it can increase the skills of the remaining workers in the innovation sector because of the diaspora channel (the intensive margin). This latter effect occurs through $\zeta(z)$, which enhances the skills of all remaining individuals in the innovation sector as long as $b>0$. The IPR regime in turn influences innovation by changing the size of the innovation sector. An increase in IPR protection enhances the attractiveness of working in the innovation sector, thus increasing its size from both ends of the spectrum: this causes a flow of low-skilled workers from the production to the innovation sector (i.e., $z_{1}$ falls) and reduces emigration (i.e., $z_{2}$ rises). Although IPRs reduce the size of the diaspora by limiting migration, the potential for absorption of the newly acquired skills from the North is higher because the diaspora effect influences a larger range of workers.

Our theory draws upon the realistic assumption that emigration may give origin to cross-border diaspora networks between skilled emigrants and natives. It turns out that in the presence of a strong IPR regime the gains in human capital deriving from the diaspora channel of knowledge are more likely to outweigh the direct drain of skills caused by emigration. As a consequence, when patents are sufficiently protected, informal networks of emigrants and people remaining at home are crucial in turning a brain drain into a brain gain. The simple setting introduced is a first step to highlight the joint role of institutions and migration in promoting growth and aims to encourage further research on the issue. It can be extended to incorporate a wider range of topics into the framework such as trade, FDI, and imitation (versus innovation) in developing countries. 


\section{A Appendix}

Assumption 1a: Inequality $z_{1}<z_{2}$ must hold so that not everyone in the innovation sector migrates. This requires

$$
\begin{aligned}
\frac{1+e-\omega_{H} Z}{\omega_{H}} & <\frac{F+\omega_{H} Z}{\omega_{M}-\omega_{H}} \\
& \Rightarrow F>\frac{\left(\omega_{M}-\omega_{H}\right)\left(1+e-\omega_{H} Z\right)}{\omega_{H}}-\omega_{H} Z .
\end{aligned}
$$

Assumption 1b: There exists a $z_{2}<\infty$ so that someone finds it optimal to migrate regardless of gains that can be realized by the migration of others. Hence, there exists a $z_{i}<\infty$. where

$$
\begin{aligned}
\omega_{M} z_{i}-e-F & >\omega_{H} z_{i}+\omega_{H} Z-e \\
& \Rightarrow F<\left(\omega_{M}-\omega_{H}\right) z_{i}-\omega_{H} Z .
\end{aligned}
$$

Putting the conditions in the two assumptions together, we prove the existence of a feasible range of $F$ where the two conditions are valid. That is, the assumption $z_{1}<z_{2}<\infty$ is viable if and only if

$$
\begin{aligned}
\left(\omega_{M}-\omega_{H}\right) z_{i}-\omega_{H} Z & >\frac{\left(\omega_{M}-\omega_{H}\right)\left(1+e-\omega_{H} Z\right)}{\omega_{H}}-\omega_{H} Z \\
\frac{\left(\omega_{M}-\omega_{H}\right)\left(1+e-\omega_{H} Z\right)}{\omega_{H}} & <\left(\omega_{M}-\omega_{H}\right) z_{i} \\
\frac{1+e-\omega_{H} Z}{\omega_{H}} & <z_{i} \\
1+e & <\omega_{H}\left(z_{i}+Z\right),
\end{aligned}
$$

which is true for all $z_{i}>z_{1}$ (see (16)). We can therefore conclude that the two assumptions can be contemporaneously viable for the entire range of skill distribution, and that given Assumptions 1 and $2, z_{1}<z_{2}<\infty$. is always true.

We have a system of two equations:

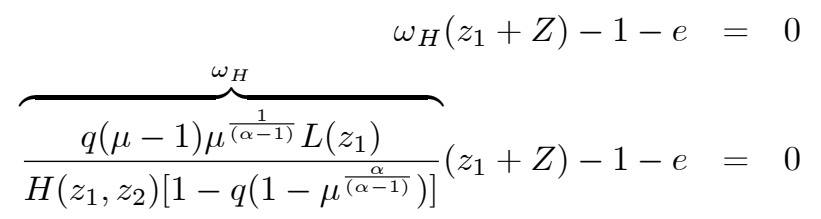




$$
\begin{aligned}
& \omega_{M} z_{2}-\omega_{H}\left(z_{2}+Z\right)-F=0 \\
& \omega_{M} z_{2}-\overbrace{\frac{q(\mu-1) \mu^{\frac{1}{(\alpha-1)}} L\left(z_{1}\right)}{H\left(z_{1}, z_{2}\right)\left[1-q\left(1-\mu^{\frac{\alpha}{(\alpha-1)}}\right)\right]}}^{\omega_{H}}\left(z_{2}+Z\right)-F=0
\end{aligned}
$$

given

$$
\frac{\partial L\left(z_{1}\right)}{\partial z_{1}}>0, \frac{\partial H\left(z_{1}, z_{2}\right)}{\partial z_{1}}<0, \frac{\partial H\left(z_{1}, z_{2}\right)}{\partial z_{2}}>0
$$

which implies

$$
\frac{\partial \omega_{H}}{\partial q}>0, \frac{\partial \omega_{H}}{\partial z_{1}}>0, \frac{\partial \omega_{H}}{\partial z_{2}}<0 .
$$

We would like to establish whether

$$
\frac{d z_{1}}{d q} \gtrless 0, \frac{d z_{2}}{d q} \gtrless 0
$$

Considering $\omega_{H}$ as a function of $z_{1}, z_{2}$, and $q$, we have the two conditions given by two functions $\Gamma_{i}\left(z_{1}, z_{2}, q\right)=0$ for $i=1,2$ :

$$
\left\{\begin{array}{l}
\Gamma_{1}\left(z_{1}, z_{2}, q\right)=-\left(z_{1}+Z\right) \omega_{H}\left(z_{1}, z_{2}, q\right)+1+e=0 \\
\Gamma_{2}\left(z_{1}, z_{2}, q\right)=\left(z_{2}+Z\right) \omega_{H}\left(z_{1}, z_{2}, q\right)+F-z_{2} \omega_{M}=0
\end{array} .\right.
$$

Subsequently, we calculate the total differentials $d \Gamma_{1}$ and $d \Gamma_{2}$ and equate them:

$$
d \Gamma_{1}=d \Gamma_{2} \Longleftrightarrow \frac{\partial \Gamma_{1}}{\partial z_{1}} d z_{1}+\frac{\partial \Gamma_{1}}{\partial z_{2}} d z_{2}+\frac{\partial \Gamma_{1}}{\partial q} d q+\frac{\partial \Gamma_{1}}{\partial Z} d Z=\frac{\partial \Gamma_{2}}{\partial z_{1}} d z_{1}+\frac{\partial \Gamma_{2}}{\partial z_{2}} d z_{2}+\frac{\partial \Gamma_{2}}{\partial q} d q+\frac{\partial \Gamma_{1}}{\partial Z} d Z
$$

Then, we consider the plane $\left(z_{1}, q\right)$ to evaluate the slope of the function $z_{1}(q)$, so we impose $d z_{2}=0$, $d Z=0$, and after calculating the first-order partial derivatives we obtain:

$$
-\left(\omega_{H}(\cdot)+\left(z_{1}+Z\right) \frac{\partial \omega_{H}}{\partial z_{1}}\right) d z_{1}-\left(z_{1}+Z\right) \frac{\partial \omega_{H}}{\partial q} d q=\left(z_{2}+Z\right) \frac{\partial \omega_{H}}{\partial z_{1}} d z_{1}+\left(z_{2}+Z\right) \frac{\partial \omega_{H}}{\partial q} d q
$$

Subsequently, we collect terms and identify the ratio of the differentials:

$$
\frac{d z_{1}}{d q}=-\frac{\left(z_{1}+z_{2}+2 Z\right) \frac{\partial \omega_{H}}{\partial q}}{\omega_{H}(\cdot)+\left(z_{1}+z_{2}+2 Z\right) \frac{\partial \omega_{H}}{\partial z_{1}}} .
$$

From the investigation of (A1) we can deduce that

$$
\frac{d z_{1}}{d q}<0 \text { as } \frac{\partial \omega_{H}}{\partial z_{1}}>0 \text { and } \frac{\partial \omega_{H}}{\partial q}>0
$$


We can repeat the same procedure by setting $d z_{1}=0$ and $d Z=0$ in the relation $d \Gamma_{1}=d \Gamma_{2}$ to establish a relationship between the differentials $d z_{2}$ and $d q$ :

$$
\begin{aligned}
& -\left(z_{1}+Z\right) \frac{\partial \omega_{H}}{\partial z_{2}} d z_{2}-\omega_{H} \frac{\partial Z}{\partial z_{2}} d z_{2}-\left(z_{1}+Z\right) \frac{\partial \omega_{H}}{\partial q} d q \\
= & \left(\omega_{H}(\cdot)-\omega_{M}+\left(z_{2}+Z\right) \frac{\partial \omega_{H}}{\partial z_{2}}+\omega_{H} \frac{\partial Z}{\partial z_{2}} d z_{2}\right) d z_{2}+\left(z_{2}+Z\right) \frac{\partial \omega_{H}}{\partial q} d q .
\end{aligned}
$$

The slope will amount to the following:

$$
\frac{d z_{2}}{d q}=-\frac{\left(z_{1}+z_{2}+2 Z\right) \frac{\partial \omega_{H}}{\partial q}}{\omega_{H}(\cdot)-\omega_{M}+\left(z_{1}+z_{2}+2 Z\right) \frac{\partial \omega_{H}}{\partial z_{2}}+2 \omega_{H} \frac{\partial Z}{\partial z_{2}}}
$$

(A3) has a form that is analogous to (A1), so we can carry out a similar investigation:

$$
\frac{d z_{2}}{d q}>0 \text { as } \omega_{H}-\omega_{M}<0, \frac{\partial \omega_{H}}{\partial z_{2}}<0, \frac{\partial Z}{\partial z_{2}}<0, \text { and } \frac{\partial \omega_{H}}{\partial q}>0
$$

We have therefore proved that

$$
\frac{d z_{1}}{d q}<0, \frac{d z_{2}}{d q}>0
$$

That is, stronger IPR protection expands the size of the innovation sector from both sides of the spectrum of skills by decreasing $z_{1}$ and increasing $z_{2}$.

Finally, to account for the general equilibrium effect, we must also derive the sign of $\frac{d z_{2}}{d z_{1}}$. Dividing (A3) by (A1) we obtain

$$
\frac{d z_{2} / d q}{d z_{1} / d q}=\frac{d z_{2}}{d z_{1}}=\frac{\omega_{H}(\cdot)+\left(z_{1}+z_{2}+2 Z\right) \frac{\partial \omega_{H}}{\partial z_{1}}}{\omega_{H}(\cdot)-\omega_{M}+\left(z_{2}+z_{1}+2 Z\right) \frac{\partial \omega_{H}}{\partial z_{2}}+2 \omega_{H} \frac{\partial Z}{\partial z_{2}}}
$$

Using the same argument as that for (A1) and (A3), we can deduce from (A4) that

$$
\frac{d z_{2}}{d z_{1}}<0
$$

This is because, given (A2), the numerator of (A4) is positive while the denominator is negative.

We have therefore proved that stronger IPR protection expands the size of the innovation sector from both sides of the spectrum of skills by decreasing $z_{1}$ and increasing $z_{2}$. Furthermore, thresholds $z_{1}$ and $z_{2}$ always move in opposite directions. 


\section{A.1 Proof of Corollary 1}

According to (6), the sign of a change in $N\left(z_{1}, z_{2}, q\right)$ is equivalent to that in $H\left(z_{1}, z_{2}, q\right)$. We therefore proceed by taking the total derivative of $H\left(z_{1}, z_{2}, q\right)$ with respect to $q$.

$$
\begin{aligned}
& \frac{d H\left(z_{1}, z_{2}, q\right)}{d q}=\frac{d \int_{z_{1}}^{z_{2}} h_{i} g(z) d z}{d q}=\frac{d \int_{z_{1}}^{z_{2}}\left[z_{i}+b \zeta(z)\right] g(z) d z}{d q}=\frac{d \int_{z_{1}}^{z_{2}}\left[z_{i}+b \int_{z_{2}}^{\infty} z g(z) d z\right] g(z) d z}{d q} \\
& =\frac{d \int_{z_{1}}^{z_{2}} z_{i} g(z) d z}{d q}+\frac{d \int_{z_{1}}^{z_{2}}\left[b \int_{z_{2}}^{\infty} z d g(z) d z\right] g(z) d z}{d q}=\frac{d \int_{z_{1}}^{z_{2}} z_{i} g(z) d z}{d q}+\frac{d\left(b\left[G\left(z_{2}\right)-G\left(z_{1}\right)\right] \int_{z_{2}}^{\infty} z d g(z) d z\right)}{d q}
\end{aligned}
$$

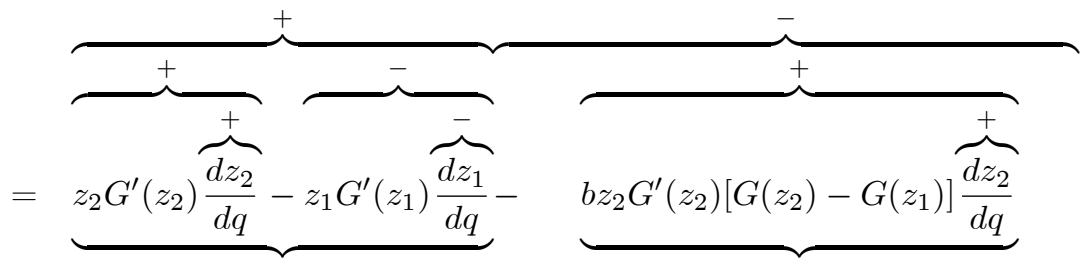

$$
\begin{aligned}
& \text { more skills enter innovation sector change in spillover amount on current workers } \\
& \text { (-) as IPRs reduce diaspora }
\end{aligned}
$$

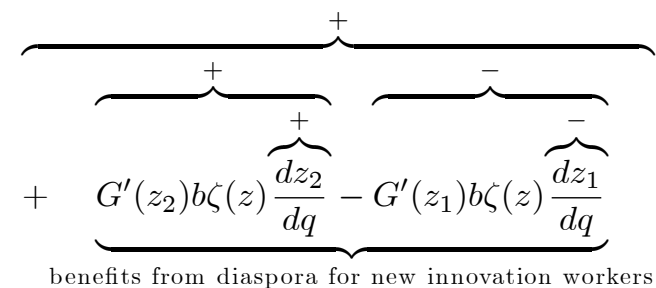

$$
\begin{aligned}
& =G^{\prime}\left(z_{2}\right) \frac{d z_{2}}{d q}\left[z_{2}+b \zeta(z)\right]-G^{\prime}\left(z_{1}\right) \frac{d z_{1}}{d q}\left[z_{1}+b \zeta(z)\right]-b z_{2} G^{\prime}\left(z_{2}\right)\left[G\left(z_{2}\right)-G\left(z_{1}\right)\right] \frac{d z_{2}}{d q} \\
& =G^{\prime}\left(z_{2}\right) \frac{d z_{2}}{d q} h\left(z_{2}\right)-G^{\prime}\left(z_{1}\right) \frac{d z_{1}}{d q} h\left(z_{1}\right)-G^{\prime}\left(z_{2}\right) \frac{d z_{2}}{d q} z_{2} b\left[G\left(z_{2}\right)-G\left(z_{1}\right)\right]
\end{aligned}
$$

The first two terms represent the positive effect of IPRs due to entry of more workers into the innovation sector and the last term is the negative diaspora effect caused by reduced migration. 


\section{A.2 Proof of Corollary 2}

According to (6), the sign of a change in $N\left(z_{1}, z_{2}, q\right)$ is equivalent to that in $H\left(z_{1}, z_{2}, q\right)$. We therefore proceed by taking the total derivative of $H\left(z_{1}, z_{2}, q\right)$ with respect to $F$.

$$
\begin{aligned}
& \frac{d H\left(z_{1}, z_{2}, q\right)}{d F}=\frac{d \int_{z_{1}}^{z_{2}} h_{i} g(z) d z}{d F}=\frac{d \int_{z_{1}}^{z_{2}}\left[z_{i}+b \zeta(z)\right] g(z) d z}{d F}=\frac{d \int_{z_{1}}^{z_{2}}\left[z_{i}+b \int_{z_{2}}^{\infty} z g(z) d z\right] g(z) d z}{d F} \\
& =\frac{d \int_{z_{1}}^{z_{2}} z_{i} g(z) d z}{d F}+\frac{d \int_{z_{1}}^{z_{2}}\left[b \int_{z_{2}}^{\infty} z g(z) d z\right] g(z) d z}{d F}=\frac{d \int_{z_{1}}^{z_{2}} z_{i} g(z) d z}{d F}+\frac{d\left(b\left[G\left(z_{2}\right)-G\left(z_{1}\right)\right] \int_{z_{2}}^{\infty} z g(z) d z\right)}{d F}
\end{aligned}
$$

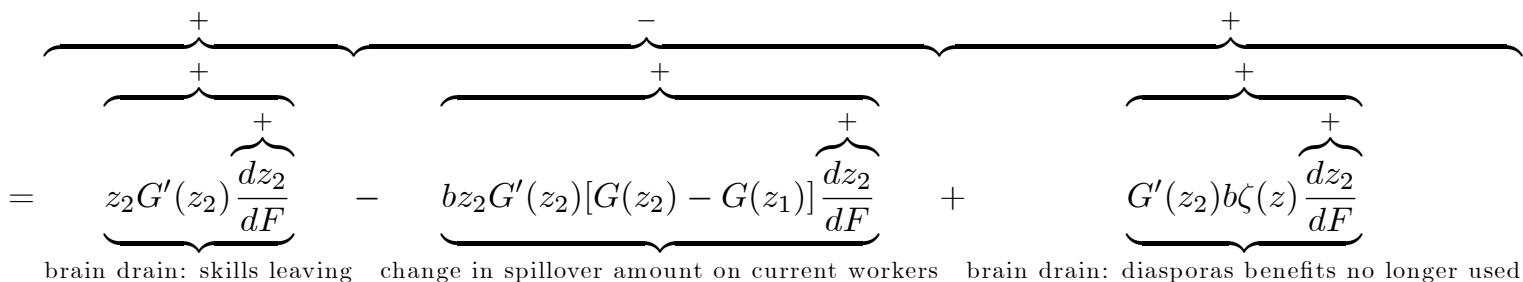

$$
\begin{aligned}
& \text { (-) as migration generates more diasporas } \\
& =G^{\prime}\left(z_{2}\right) \frac{d z_{2}}{d F}\left\{z_{2}\left(1-b\left[G\left(z_{2}\right)-G\left(z_{1}\right)\right]\right)+b \zeta(z)\right\}
\end{aligned}
$$

We obtain $\frac{d H\left(z_{1}, z_{2}, q\right)}{d F}<0$ if and only if $z_{2} b\left[G\left(z_{2}\right)-G\left(z_{1}\right)\right]>z_{2}+b \zeta(z)$, which can be simplified to $z_{2} \Phi>h\left(z_{2}\right)$. Note the extra term on the RHS with respect to Proposition 1 that appears here as we are calculating the number of inventions as opposed to a pure brain drain. That is, when talking in terms of total productivity per workers, those who leave take with them not only their innate abilities but also what they learn from diasporas. Rewriting the new condition as

$$
\Phi>1+\frac{b \zeta(z)}{z_{2}}
$$

it is more likely to be satisfied under strong IPR enforcement as an increase in $q$ increases the RHS through a higher $z_{2}$ and a lower $z_{1}$ (expanding the innovation sector), and decreases the LHS through a higher $z_{2}$ (less brain drain and more remaining workers to benefit from diasporas). Setting the initial (pre-existing) level of diaspora knowledge flow equal to zero, the condition simplifies to that obtained in Proposition 1. 


\section{References}

[1] Agrawal, A., Kapur, D. and McHale, J. (2011), "Brain Drain or Brain Bank? The Impact of Skilled Emigration on Poor-Country Innovation", Journal of Urban Economics, 69(1): 43-55.

[2] Beine, M. Docquier, F. and Ozden, C. (2011), "Diasporas", Journal of Development Economics, 95(1): $30-41$.

[3] Beine, M. Docquier, F. and Rapoport, H. (2001), "Brain Drain and Economic Growth: theory and evidence", Journal of Development Economics, 64: 275-289.

[4] Beine, M. Docquier, F. and Rapoport, H. (2008), "Brain Drain and Human Capital Formation in Developing Countries: Winners and Losers", Economic Journal 118(528): 631-652.

[5] Berry, R. and Soligo, R. (1969), "Some Welfare Aspects of International Migration", Journal of Political Economy 77(5): 778-94.

[6] Bhagwati, J. and Hamada, K. (1974), "The Brain Drain, International Integration of Markets for Professionals and Unemployment: A theoretical analysis", Journal of Development Economics: $1(1), 19-42$.

[7] Bhagwati, J. and Rodriguez, C. (1975), "Welfare-Theoretical Analyses of the Brain Drain", Journal of Development Economics 2(3): 195-221.

[8] Chen, Y. and Puttinan, T. (2005), "Intellectual Property Rights and Innovation in Developing Countries", Journal of Development Economics 78(2): 474-493.

[9] Davis, C. and Naghavi, A. (2011), "Offshoring Production: A Simple Model of Wages, Productivity, and Growth", Economic Inquiry 49(2): 334-348.

[10] Docquier, F., and Rapoport, H. (2012), "Globalization, Brain Drain and Development", Journal of Economic Literature, 50: 681-730.

[11] Domingues Dos Santos, M., and Postel-Vinay, F. (2003), "Migration as a Source of Growth: The Perspective of a Developing Country", Journal of Population Economics, 16(1): 161-175.

[12] Dustmann, C., Fadlon I., and Weiss Y. (2011), "Return Migration, Human Capital Accumulation and the Brain Drain", Journal of Development Economics, 95(1): 58-67.

[13] Grossman, G.M. and Lai, E.L.-C. (2004), "International Protection of Intellectual Property", American Economic Review 94(5): 1635-1653.

[14] Helpman, E., Itskhoki, O., and Redding, S. (2009), "Unequal Effects of Trade on Workers with Different Abilities", Journal of the European Economic Association, 8(2-3): 456-466. 
[15] Helpman, E., Itskhoki, O., and Redding, S. (2010), "Inequality and Unemployment in a Global Economy", Econometrica 78(4): 1239-1283.

[16] Helpman, E., Itskhoki, O., and Redding, S. (2011), "Trade and Labor Market Outcomes", in Acemoglu, D., Arellano, M., and Dekel, E. (eds.), Advances in Economics and Econometrics: Theory and Applications, Tenth World Congress of the Econometric Society.

[17] Iranzo, S. and Peri, G. (2009),"Migration and trade: Theory with an application to the EasternWestern European Integration", Journal of International Economics 79(1): 1-19.

[18] Keller, W. (2004), "International Technology Diffusion", Journal of Economic Literature, 42: 752-782.

[19] Kerr, W. R. (2008), "Ethnic scientific communities and International Technology Diffusion", The Review of Economics and Statistics 90(3): 518-537.

[20] Maskus, K. (2000), "Intellectual Property Rights in the Global Economy", Washington, DC: Institute for International Economics.

[21] McAusland, C. and Kuhn, P. (2011), "Bidding for Brains: Intellectual Property Rights and the International Migration of Knowledge Workers", Journal of Development Economics, 95(1): $77-87$.

[22] Mayr, K. and Peri, G. (2009), "Return Migration as a Channel of Brain Gain", Berkeley Electronic Journal of Economic Analysis \& Policy, Contributions 9(1): Article 49.

[23] Meyer, J. B. (2001), "Network Approach vs. Brain Drain: Lessons From the Diaspora", International Migration Quarterly Issue, 39(5): 91-110.

[24] Meyer J. B. and Brown, M. (1999), "Scientific Diasporas, a New Approach to the Brain Drain", Discussion Paper no. 41, Management of Social Transformation, UNESCO, Paris.

[25] Miyagiwa, K. (1991), "Scale Economies in Education and the Brain Drain Problem", International Economic Review 32(3): 743-759.

[26] Mountford, A. (1997), "Can a Brain Drain Be Good for Growth in the Source Economy?", Journal of Development Economics 53(2): 287-303.

[27] Naghavi, A. and Strozzi, C. (2014), "Can Intellectual Property Rights Protection Generate Brain Gain from International Migration?", mimeo.

[28] Oettl, A. and Agrawal, A. (2008), "International Labor Mobility and Knowledge Flow Externalities", Journal of International Business Studies 39(8): 1242-1260. 
[29] Ohnsorge, F. and Trefler, D. (2007), "Sorting it Out: International Trade and Protection with Heterogeneous Workers", Journal of Political Economy 115(5): 868-892.

[30] Park, W. G. (2008), "International Patent Protection: 1960-2005", Research Policy 37: 761766.

[31] Parello, C. (2008), "A North-South Model of Intellectual Property Rights Protection and Skill Accumulation", Journal of Development Economics 85(1-2): 253-281.

[32] Pedersen, J. P., Pytlikova, M. and Smith, N. (2008), "Selection and network effects - Migration flows into OECD countries 1990-2000", European Economic Review 52: 1160-1186.

[33] Saggi, K. (2002), "Trade, Foreign Direct Investment, and International Technology Transfer: A Survey", World Bank Research Observer, 17(2): 191-235.

[34] Saint-Paul, G. (2003), "Growth Effects of Nonproprietary Innovation", Journal of European Economic Association 1(2-3): 429-439.

[35] Saint-Paul, G. (2004), "Are Intellectual Property Rights Unfair?", Labour Economics 11: 129144.

[36] Spilimbergo, A. (2009), "Democracy and Foreign Education", American Economic Review 99 (1): $528-43$.

[37] Stark, O., Helmenstein, C. and Prskawetz, A. (1997), "A Brain Gain with a Brain Drain", Economics Letters 55: 227-234.

[38] The Economist, "Give Me Your Scientists...", March 7, 2009.

[39] The Economist, "The Magic of Diasporas", November 19, 2011.

[40] Williams, A. M. (2007), "Listen to Me, Learn with Me: International Migration and Knowledge Transfer", British Journal of Industrial Relations, 45(2): 361-382.

[41] WIPO (2012), "World Intellectual Property Indicators", WIPO Economics \& Statistics Series, WIPO.

[42] Yeaple, S. (2005), "A Simple Model of Firm Heterogeneity, International Trade, and Wages", Journal of International Economics 65: 1-20. 
The role of diaspora networks and IPR protection in international scientific collaboration

\begin{tabular}{lcc}
\hline & $(1)$ & $(2)$ \\
\hline IPR $_{-1}$ & $-0.345^{* *}$ & $-0.535^{* *}$ \\
& $(0.160)$ & $(0.254)$ \\
Population -1 & $1.687^{* *}$ & 0.722 \\
& $(0.811)$ & $(0.953)$ \\
GDP p.c. -1 & 0.583 & 0.345 \\
& $(0.377)$ & $(0.388)$ \\
Emigr. index (patents) -1 $^{-1}$ & $-4.070^{* *}$ & \\
Emigr. index (patents) -1 X IPR-1 & $(1.798)$ & \\
& $0.718^{* *}$ & $-3.747^{* *}$ \\
Emigr. index (R\&D) -1 & $(0.335)$ & $(1.554)$ \\
& & $0.798^{*}$ \\
Emigr. index (R\&D) -1 X IPR-1 & & $(0.435)$ \\
Constant & & -9.333 \\
& & $(18.658)$ \\
Observations & $-28.991^{*}$ & 105 \\
Adj. R-squared & $(15.815)$ & 0.659 \\
Time Effects & & Yes \\
Number of groups & 105 & 35 \\
\hline
\end{tabular}

Note: Robust standard errors in parentheses, clustered at country level. * significant at $10 \% ;{ }^{* *}$ significant at $5 \%$; ${ }^{* * *}$ significant at $1 \%$. The dependent variable is the number of inventors from around the world which reside in a country different from that of the PCT applicant. IPR is the index of intellectual property rights protection. Emigr. index (patents) is the emigration index based on the number of worldwide patents granted to the residents of each destination country, while Emigr. index (R\&D) is the emigration index based on R\&D expenditure in destination. Emigr. index (patents) $)_{-1} \times I_{P R_{-1}}$ and Emigr. index (R\&D) $)_{-1} \times I P_{-1}$ are the interaction terms. Inventors, patents, emigration stock, population and GDP per capita are in logarithms. All estimations are in fixed effects. 
Figure 1.

Stronger IPRs Enforcement

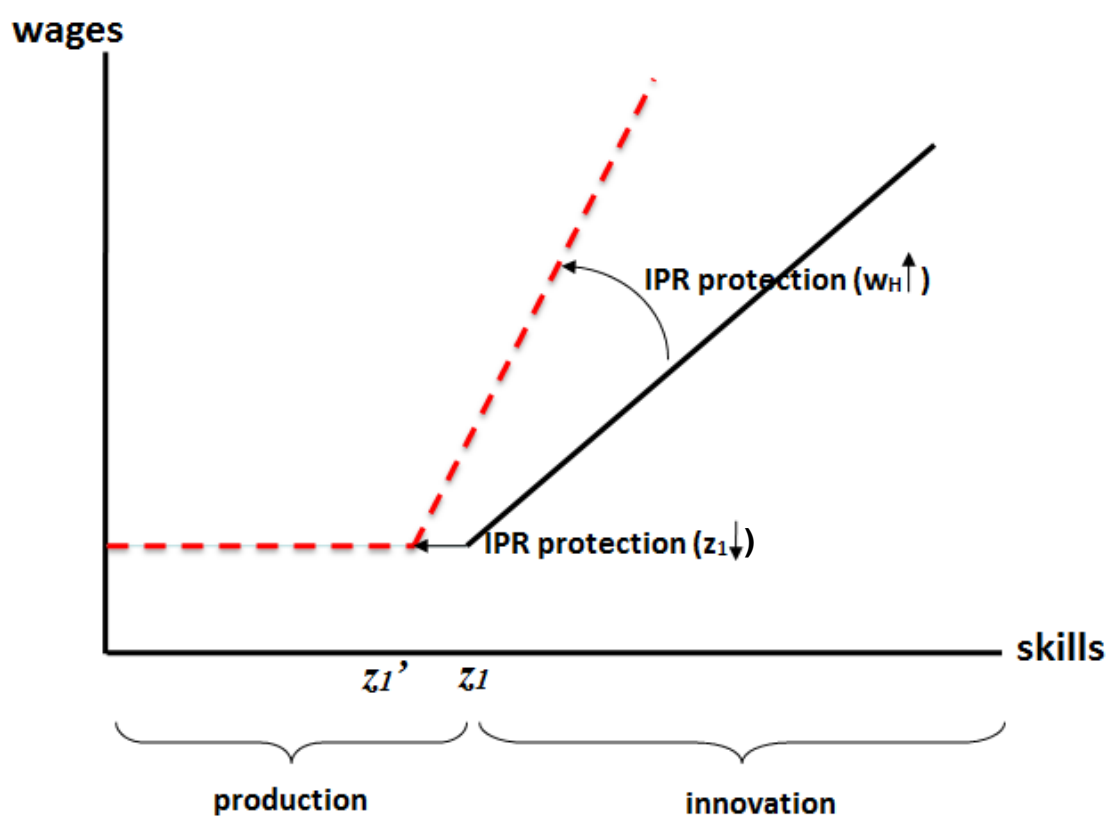

Figure 2.

Diaspora Gains

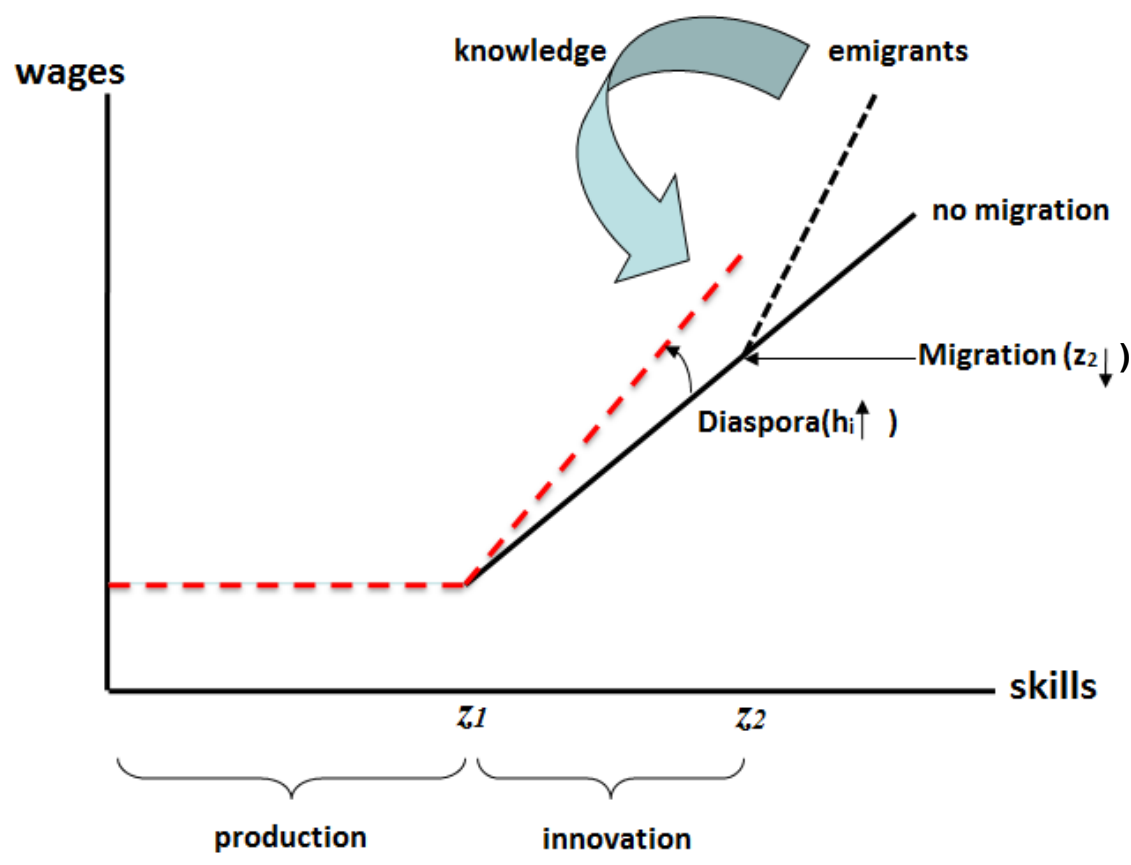


Figure 3.

The Impact of IPRs on Diaspora

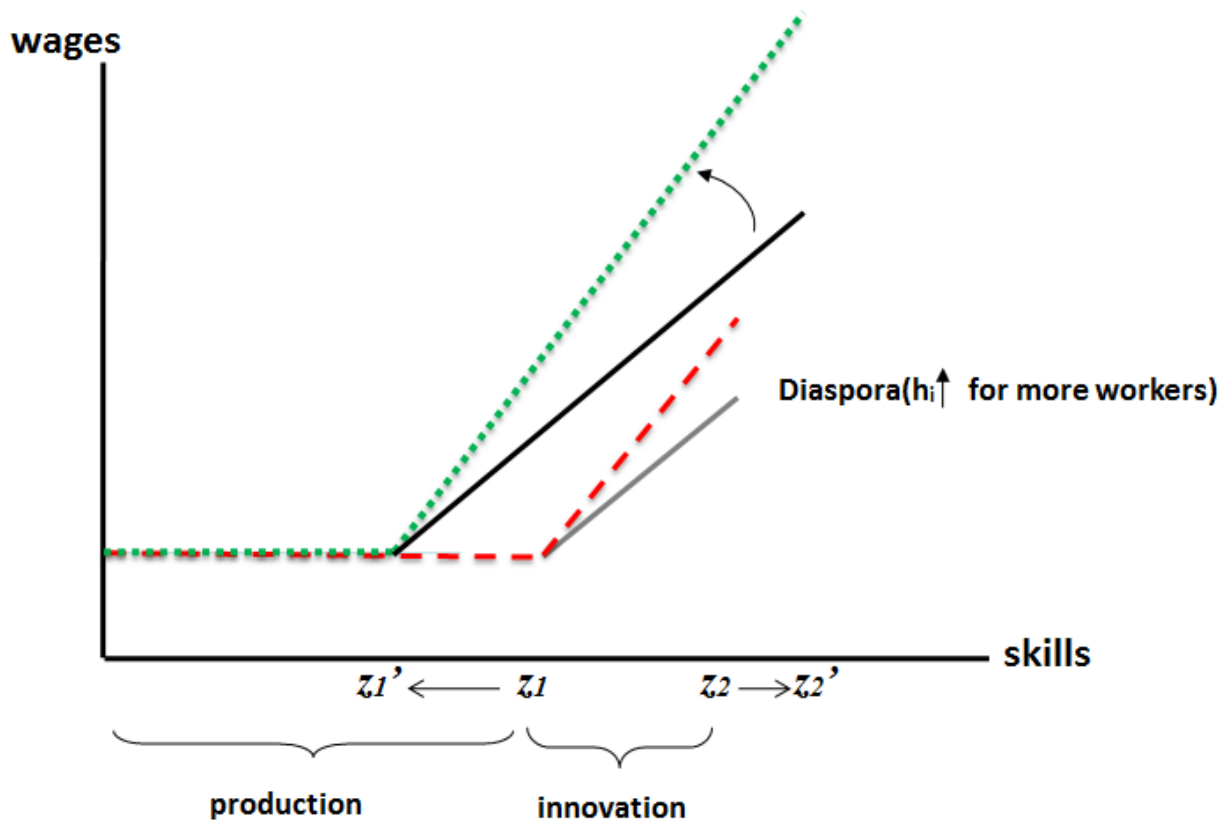

